\title{
Article \\ Chemical Composition of Hexane-Extracted Plectranthus amboinicus Leaf Essential Oil: Maximizing Contents on Harvested Plant Materials
}

\author{
Nur Suhanawati Ashaari ${ }^{1}$ (D), Nurul Elyani Mohamad ${ }^{2}{ }^{D}$, Amirul Hafizin Afzinizam ${ }^{1}$, Mohd-Hairul Ab. Rahim ${ }^{3}$, \\ Kok Song Lai ${ }^{4}$ and Janna Ong Abdullah ${ }^{1, * \mathbb{D}}$
}

1 Department of Cell and Molecular Biology, Faculty of Biotechnology \& Biomolecular Sciences, Universiti Putra Malaysia, UPM Serdang, Seri Kembangan 43400, Selangor, Malaysia; suhana_bio@yahoo.com (N.S.A.); hafizin25@gmail.com (A.H.A.)

2 Biotechnology Research Institute, Universiti Malaysia Sabah, Jalan UMS, Kota Kinabalu 88400, Sabah, Malaysia; elyani.mohamad@ums.edu.my

3 Department of Industrial Biotechnology, Faculty of Industrial Sciences and Technology, Universiti Malaysia Pahang, Gambang, Kuantan 26300, Pahang, Malaysia; hairul.biotekupm@gmail.com

4 Health Sciences Division, Abu Dhabi Women's College, Higher Colleges of Technology, Abu Dhabi 41012, United Arab Emirates; laikoksong@gmail.com

* Correspondence: janna@upm.edu.my

check for updates

Citation: Ashaari, N.S.; Mohamad, N.E.; Afzinizam, A.H.; Ab. Rahim, M.-H.; Lai, K.S.; Ong Abdullah, J. Chemical Composition of Hexane-Extracted Plectranthus amboinicus Leaf Essential Oil: Maximizing Contents on Harvested Plant Materials. Appl. Sci. 2021, 11, 10838. https://doi.org/10.3390/ app112210838

Academic Editor: Ramona Iseppi

Received: 7 May 2021

Accepted: 24 May 2021

Published: 16 November 2021

Publisher's Note: MDPI stays neutral with regard to jurisdictional claims in published maps and institutional affiliations.

Copyright: (c) 2021 by the authors. Licensee MDPI, Basel, Switzerland. This article is an open access article distributed under the terms and conditions of the Creative Commons Attribution (CC BY) license (https:// creativecommons.org/licenses/by/ $4.0 /)$.

\begin{abstract}
Plectranthus amboinicus (Lour.) Spreng, also known locally as "Bangun-bangun", is an aromatic medicinal herb known for its therapeutic and nutritional properties attributed to its terpenoidrich phytochemicals. Information to assist in initiating appropriate harvesting time to maximize the yield of targeted chemicals in harvested plant tissues remains an issue that is seldom highlighted. This study reports on the essential oil distribution in P. amboinicus leaves, and total phenolic and flavonoid contents, in addition to GC-MS analysis of hexane extracts of the leaf samples collected at various times throughout the day. The influence of environmental factors on $\gamma$-terpinene, $\mathrm{p}$-cymene, carvacrol, and thymoquinone are also discussed. Oil Red O staining showed the highest oil deposition at 2 p.m., which was consistent with the phenolic and flavonoid contents of this plant. GC-MS analysis of the leaf extract showed carvacrol (47.00-60.00\%), $\gamma$-terpinene (8.00-10.00\%), caryophyllene ( $6.00 \%)$, p-cymene (4.90-6.50\%), trans- $\alpha$-bergamotene (4.70-5.00\%), and thymoquinone (3.30-5.60\%) were the major components of this plant. Interestingly, thymoquinone, a phytochemical associated with Nigella sativa, was also detected in this hexane-extracted sample with maximum accumulation during midday and a decrease at night, which could be due to the lower temperature and dimmer light conditions. The chemical polymorphism in the oil content indicated that environmental factors such as light exposure and temperature should be considered during harvesting to ensure consistent quality of the phytochemicals extracted from the plant materials. This study indicates that oversight in selecting plant materials might compromise the yield of quality phytochemicals extracted from harvested tissues.
\end{abstract}

Keywords: essential oil; Lamiaceae; Plectranthus amboinicus; terpenoids; carvacrol; thymoquinone

\section{Introduction}

Plectranthus amboinicus (Lour.) Spreng or locally known as "Bangun-bangun" in Malaysia is a medicinal herb that belongs to the Lamiaceae family, including sage, thyme, basil, and oregano herbs. It can be found naturally throughout the tropics and warm regions of Africa, Asia, and Australia [1]. This plant (Figure 1) is characterized by its green, succulent, heart-shaped velvet leaves with serrated edges. It possesses a distinctive oregano-like flavor and aroma that make it an excellent choice for culinary purposes. The leaves of this plant are often eaten raw or drunk as tea and juice due to its high nutritional contents, such as those of calcium, potassium, and iron, which are necessary for healthy 
bones, heart, and kidneys, while aiding with oxygen transportation of red blood cells throughout the body [2].

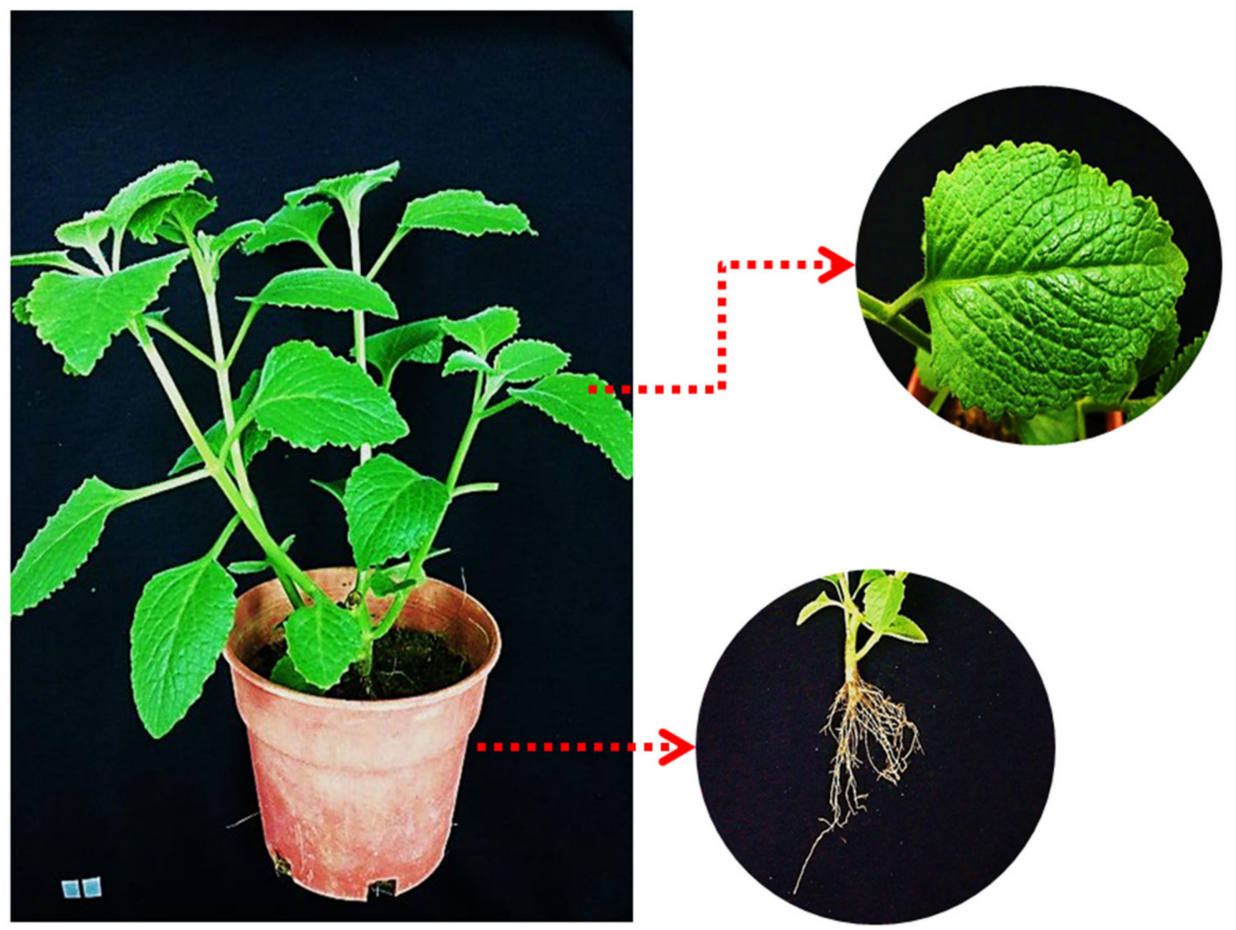

Figure 1. Plectranthus amboinicus.

This plant has been used traditionally for the treatment of coughing, sore throat, nasal congestion, and animal and insect bites, in addition to use as a breast milk stimulant, for hundreds of years $[3,4]$. During the past decade, researchers have begun to concentrate their interests on P. amboinicus, as demonstrated by the growing number of publications related to the bioactivities of P. amboinicus extract. This plant extract exhibited antibacterial activity against methicillin-resistant Staphylococcus aureus in a murine model [5] and was proven to be effective against reproductive tract infections caused by Candida albicans, Proteus vulgaris, and Klebsiella pnumoniae [6]. This shows the potential application of P. amboinicus extract as a source of antimicrobial compounds, with growing global concerns related to the emergence of antibiotic-resistant bacteria. A study by Gurgel et al. [7] demonstrated a significant reduction in paw edema and inhibition of S-180 tumor in mice treated with the hydroalcoholic extract of $P$. amboinicus, which provided preliminary evidence that this plant extract possessed anti-inflammatory and antitumor activities. Various literature also reported that P. amboinicus possessed larvicidal [8], antithrombotic, and antioxidant activities [9].

The therapeutic and medicinal properties of P. amboinicus are mainly attributed to its natural phytochemical compounds, either in the essential oil or the plant extract. A literature survey revealed the occurrence of 76 volatile and 30 non-volatile compounds, such as monoterpenoids, diterpenoids, sesquiterpenoids, phenolic, flavonoids, esters, and aldehydes, in the essential oil extracted from the leaves and stems of P. amboinicus [1]. Generally, the essential oil of P. amboinicus contains high amounts of bioactive compounds, mainly monoterpenoids such as carvacrol, thymol, $\gamma$-terpinene, $\alpha$-terpineol, and p-cymene, with various pharmacological properties. The antimicrobial activity of the P. amboinicus extract may be explained by the presence of $\gamma$-terpinene and $\alpha$-terpineol, which are effective against both Gram-positive and Gram-negative bacteria, such as Listeria monocytogenes, Streptococcus pyogenes, Proteus vulgaris, and Escherichia coli, by inducing cell lysis through leakage of protein and lipids [10]. Previous studies have also demonstrated that carvacrol significantly inhibited tumor cell proliferation, metastasis, and invasion, and induced 
apoptosis in human oral squamous cell carcinoma [11]. These unique properties highlight the potential of terpenoids in pharmaceutical application. The current work describes the oil distribution in the P. amboinicus leaf based on morphological and sensory assessments, total phenolic and total flavonoid contents, and GC-MS analysis of the hexane-extracted essential oil obtained at different times.

\section{Materials and Methods}

\subsection{Plant Materials}

Plectranthus amboinicus was obtained from purchased plants that were maintained at the BioTech2 Building, Faculty of Biotechnology and Biomolecular Sciences, Universiti Putra Malaysia $\left(3^{\circ} 00^{\prime} 26.4^{\prime \prime} \mathrm{N} 101^{\circ} 42^{\prime} 19.3^{\prime \prime}\right.$ E). Authentication of the plant was conducted by Dr Shamsul Khamis and deposited as a herbarium specimen with the voucher number UKMB40411 at the Universiti Kebangsaan Malaysia (UKM), Bangi, Selangor, Malaysia [12].

\subsection{Sensory Evaluation (Direct Olfactory Detection) of Plectranthus amboinicus Leaf Volatiles}

The scent analysis of P. amboinicus leaves was carried out by a group of students consisting of 5 members. The students were briefed and trained prior to the experiment. The leaves from the third node, counting from the shoot apical meristem of the plant, were chosen in this study. Five leaves were used in each of the time points and the test was divided into two sessions. In the first session, each student was given a leaf and was asked to rub the leaf using both of their hands before positioning the leaf $5 \mathrm{~cm}$ from their noses. In the second session, a new leaf was provided, and they were asked to position the leaves $5 \mathrm{~cm}$ from their noses. The scent emitted from the leaves from both sessions were evaluated and scaled from 0 to 6 , with 6 as the strongest scent emitted and 0 as no scent detected.

\subsection{Oil Red O Histochemical Staining of Plectranthus amboinicus Leaf Using Freehand Fresh Stain Method}

The leaves from the third node, counting from the shoot apical meristem of the plant, were harvested at three designated time points and freehand cut using a sharp razor blade into thin layers and placed on microscope slides (the length for each leaf section measured approximately $0.5 \pm 0.05 \mathrm{~cm})$. Each section was rinsed with $0.5 \mathrm{~mL}$ of $60 \%(v / v)$ isopropanol and stained with $0.8 \mathrm{~mL}$ of Oil Red O solution (Sigma Aldrich, St Louis, MO, USA ) for $15 \mathrm{~min}$. Next, the section was rinsed with $0.3 \mathrm{~mL}$ of $60 \%(v / v)$ isopropanol and mounted on dibutyl phthalate polystyrene xylene (DPX) mounting medium. The section was covered with a clear coverslip, and the presence of oil droplets (stained red) was observed under an inverted microscope (Nikon, Tokyo, Japan) at $40 \times$ and $200 \times$ magnifications.

\subsection{Oil Quantification of Stained Leaf Sections}

For the quantification of lipid accumulation, an optical density (OD) assessment was conducted to measure the intensity of the red pigment in the leaf, representing the proportion of the essential oil in the tissue sample at the specific time points. In brief, the leaves from three designated time points ( 8 a.m., 2 p.m., and 8 p.m.) were stained with the Oil Red O. Each stained leaf was cut, rinsed with $0.3 \mathrm{~mL}$ of $60 \%(\mathrm{v} / \mathrm{v})$ isopropanol, and then placed inside a $2 \mathrm{~mL}$ Eppendorf tube. Then, $150 \mu \mathrm{L}$ of absolute isopropanol was added to the tube and vortexed for $30 \mathrm{~min}$. Next, $100 \mu \mathrm{L}$ of the extract was aliquoted into a 96-well microtiter plate. The OD was measured to quantify the intensity of the extracts at $490 \mathrm{~nm}$ using an ELISA plate reader (Bio-Tek Instruments, Winooski, VT, USA). One hundred percent isopropanol was used as a blank. The experiment was performed in triplicate.

\subsection{Essential Oil Extraction from Fresh Plectranthus amboinicus Leaves Using a Non-Polar Solvent}

Plectranthus amboinicus essential oil (EO) was extracted from fresh leaves according to Mohd-Hairul et al. [13] using a non-polar hexane solvent (Sigma, USA). A total of $100 \mathrm{~g}$ of fresh leaves was harvested respectively at 8 a.m., 2 p.m., and 8 p.m. and ground separately in a mixer grinder. The ground leaves were then immersed in $800 \mathrm{~mL}$ hexane for $48 \mathrm{~h}$, 
and the extract was filtered using a Whatman filter paper $(125 \mathrm{~mm}$, No. 4$)$ to remove the residues. Next, the extract was concentrated using a rotary evaporator (Buchi, Switzerland) with the water bath set at $50{ }^{\circ} \mathrm{C}$. The concentrated extract paste was dissolved in $3 \mathrm{~mL}$ hexane and subjected to the total phenolics, total flavonoids, and GC-MS analyses.

\subsection{Total Phenolics Content Assay (TPC) of Plectranthus amboinicus Essential Oil Extract}

The total phenolics content of P. amboinicus oil extract was determined by the FolinCiocalteau method according to Mohamad et al. [14]. The Folin-Ciocalteau (FC) reagent (Sigma Aldrich, St Louis, MO, USA) was pre-prepared using a 1:10 ratio of FC reagent to distilled water. Twenty microliters of the extract were mixed with $100 \mu \mathrm{L}$ of FC reagent for $5 \mathrm{~min}$. Then, $80 \mu \mathrm{L}(7.5 \% \mathrm{w} / \mathrm{v})$ of sodium carbonate solution (Sigma, USA) was added and thoroughly mixed before incubation at room temperature for $2 \mathrm{~h}$. The absorbance reading of the mixture was then measured at $765 \mathrm{~nm}$ using an ELISA plate reader (Bio-Tek Instruments, USA). A calibration curve was plotted using a standard solution of gallic acid, and the results were expressed as mg gallic acid equivalent (GAE) per $1 \mathrm{~g}$ of oil.

\subsection{Total Flavonoids Content (TFC) of Plectranthus amboinicus Essential Oil Extract}

The total flavonoids content of P. amboinicus essential oil extract was determined using the colorimetric assay as described by Aguiar et al. [15] with some modifications. Briefly, $150 \mu \mathrm{L}$ of $P$. amboinicus oil extract was mixed with $9 \mu \mathrm{L}$ of $5 \%(w / v) \mathrm{NaNO}_{2}$ solution. After 6 min of incubation in the dark, $9 \mu \mathrm{L}$ of $10 \%(w / v) \mathrm{AlCl}_{3}$ solution was added, and the mixture was incubated in the dark for $5 \mathrm{~min}$. Then, the mixture was added to $60 \mu \mathrm{L}$ of $1 \mathrm{M}$ $\mathrm{NaOH}$ solution followed by $72 \mu \mathrm{L}$ of distilled water. The mixture was thoroughly mixed and allowed to stand for $5 \mathrm{~s}$. The absorbance was measured at $430 \mathrm{~nm}$ using the ELISA plate reader (Bio-Tek Instruments, USA). Catechin was used as a standard in this study, and the results were expressed as mg catechin equivalent $(\mathrm{CE})$ per $1 \mathrm{~g}$ of oil.

\subsection{GC-MS Analysis of Plectranthus amboinicus Essential Oil Extract}

The P. amboinicus essential oil extract was analyzed using an Agilent 7890 gas chromatograph coupled to an Agilent 5975 quadrupole mass detector (Agilent Technologies, Santa Clara, CA, USA). One microliter of the essential oil was injected into the GC injection port with a 1:50 split mode and separated on a HP-5MS capillary column $(30 \mathrm{~m} \times 250 \mu \mathrm{m}$ inner diameter $\times 0.25 \mu \mathrm{m}$ film thickness) with helium carrier gas flow rate set at $1 \mathrm{~mL} / \mathrm{min}$. The oven temperature was initially maintained at $40^{\circ} \mathrm{C}$ for $2 \mathrm{~min}$, followed by a two-step temperature increase to $175{ }^{\circ} \mathrm{C}$ at a rate of $5{ }^{\circ} \mathrm{C} / \mathrm{min}$, then to $250{ }^{\circ} \mathrm{C}$ at $90{ }^{\circ} \mathrm{C} / \mathrm{min}$. The ion source temperature and transfer line temperature were set at 220 , and $280^{\circ} \mathrm{C}$, respectively, and electron impact mass spectra were recorded at $70 \mathrm{eV}$ ionization energy. The volatile compounds were identified by mass spectra comparison using MSD Chemstation Enhanced Data Analysis Software (E.02.02.1431 version, Agilent Technologies) and the National Institute of Standards and Technology library database (NIST 14).

\section{Results and Discussion}

\subsection{Sensory Evaluation (Direct Olfactory Detection) of Plectranthus amboinicus Leaf Volatiles}

In this study, evaluation of the scent emitted by the plant showed that the scent was produced at a high level at night ( 8 p.m.) and in the morning (8 a.m.) when the light intensity was low (Figure 2). Based on this result, there is a high possibility that P. amboinicus possesses a Crassulacean Acid Metabolism (CAM) photosynthesis, in which the thick cuticle and the stomata remain closed during strong daylight to reduce the transpiration rate and minimize water loss through epidermal cells and stomatal openings [16]. The data also demonstrated that rubbing the leaf enhanced the smell intensity more than one-fold compared to the undisturbed leaves. In the plant, it has been reported that the glandular and non-glandular trichomes are the two main structures that store the essential oil, and are found on both the adaxial and abaxial surfaces of the leaves, stem, and petiole [17]. The rubbing action on the leaves may cause the non-glandular trichomes and/or glandular 
trichomes to burst due to the applied mechanical stress, thus facilitating the release of the volatile essential oil. A similar study was reported by Sharma et al. [18] using the menthol mint plant (Mentha arvencic L.).

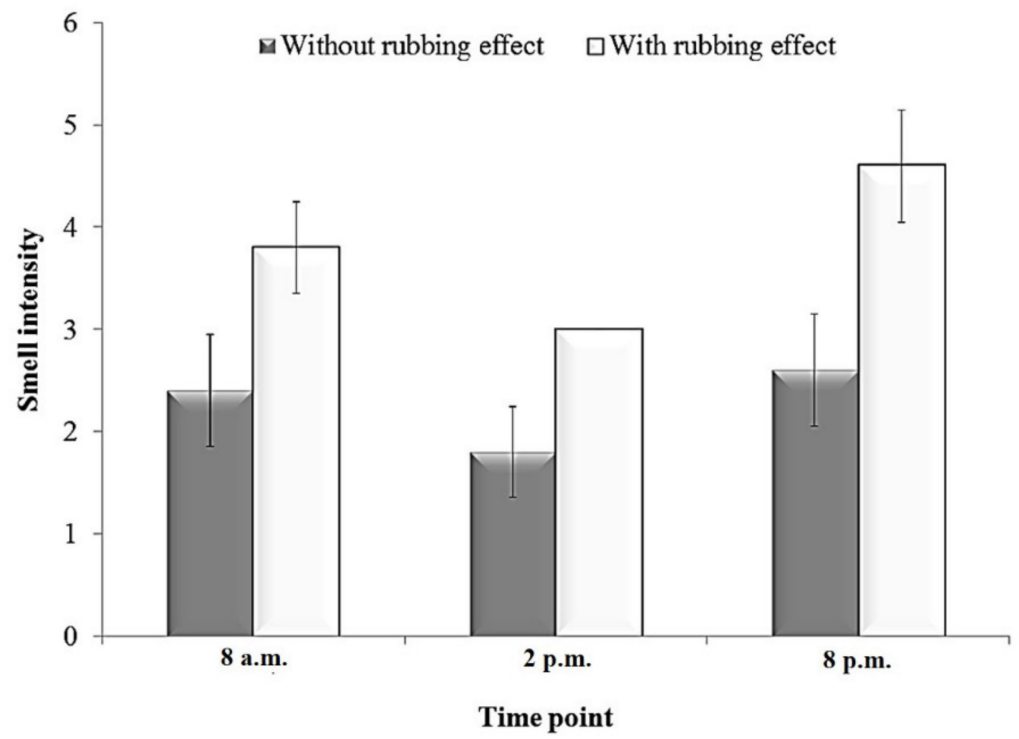

Figure 2. Effects of rubbing on the level of scent emitted by the leaves of Plectranthus amboinicus detected at a distance of $5 \mathrm{~cm}$ from the human nose. Scent intensity was evaluated based on a scale that ranged from 0 to 6 , with 6 as the strongest and 0 as no scent detected.

\subsection{Oil Red O Histochemical Staining of Plectranthus amboinicus Leaf Using Freehand Fresh} Stain Method

The relationship between the scent emitted from the leaf and the essential oil accumulated in the leaf was further extrapolated from the histochemical staining performed using Oil Red $\mathrm{O}$ as depicted in Figure 3. Accumulation of lipid droplets (red color) could be observed from the 8 p.m. leaf samples. The assay was further quantified using a spectrophotometer, as summarized in Figure 4. The highest reading for the essential oil was obtained from the leaves harvested at 8 p.m., and this result was consistent with the Oil Red O staining and sensory analyses. We hypothesized that the scent emitted from P. amboinicus leaf directly correlates with the production of the essential oil at different time points.

\subsection{Total Phenolics (TFC) and Total Flavonoids (TFC) Contents of Plectranthus amboinicus Essential Oil Extract}

The $P$. amboinicus essential oil has been reported to consist of 76 volatile constituents, and the oil is rich with oxygenated monoterpenes, monoterpene hydrocarbons, oxygenated sesquiterpenes, and sesquiterpene hydrocarbons, whereby thymol and carvacrol are the two major phenolic compounds [1,19]. Figure 5 exhibits the TPC and TFC of P. amboinicus essential oil analyzed at three different time points. Data demonstrated that the highest values of TPC and TFC were recorded at 2 p.m. and the lowest at 8 p.m. Notably, bioactive compound accumulation varies in different plants and is dependent on numerous factors, including light exposure and temperature [20]. To further investigate this issue, GCMS analysis was conducted to identify the essential oil components at the same three time points. 

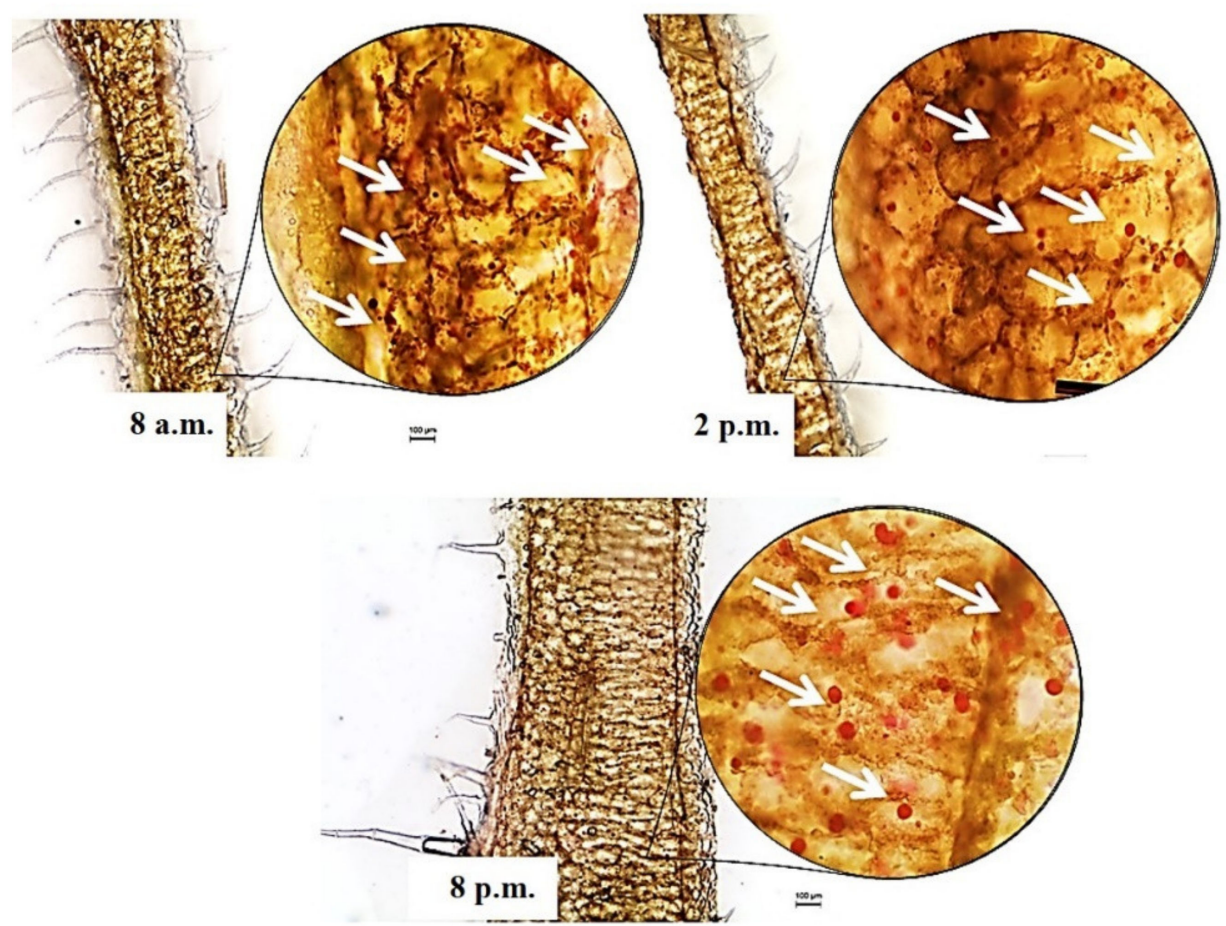

Figure 3. Photomicrographs of Plectranthus amboinicus leaf at $40 \times$ and $200 \times$ magnifications. White arrows indicate lipid droplets in the cross-sectioned leaf slices stained with Oil Red $\mathrm{O}$ and viewed at $200 \times$ magnification.

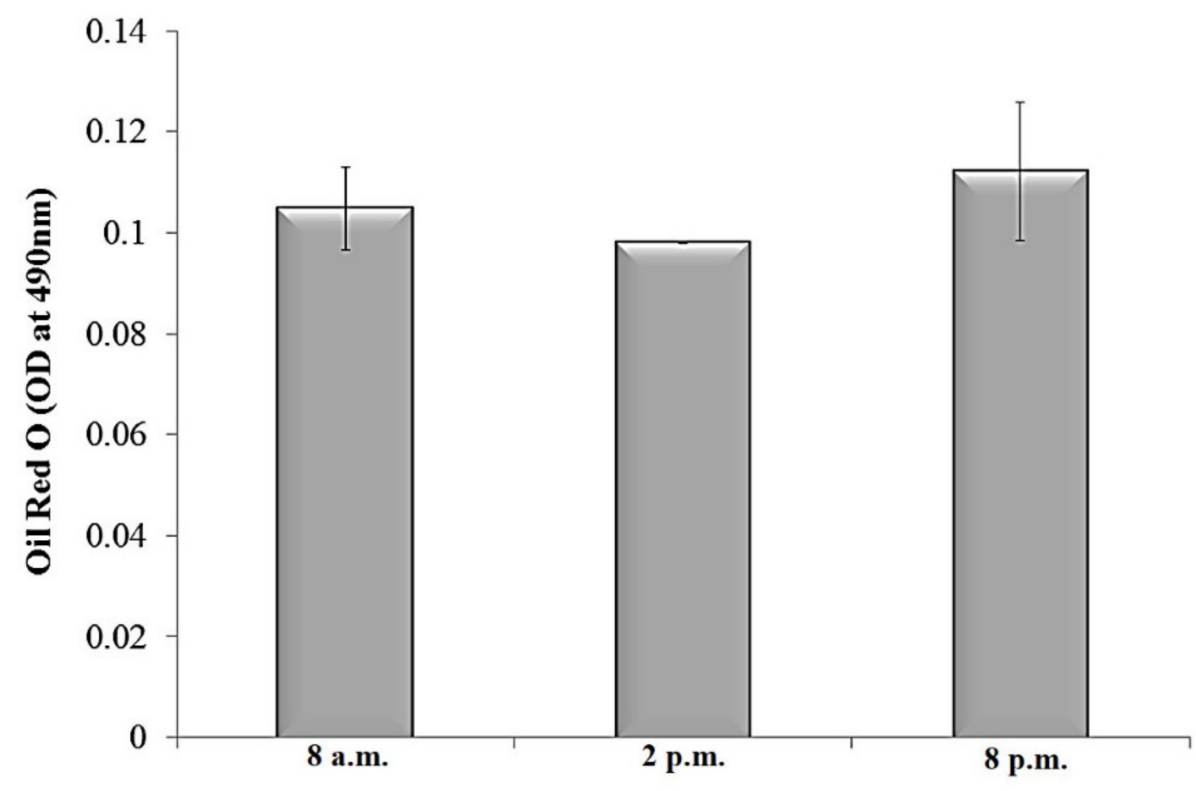

Time point

Figure 4. Spectroscopy quantification at $490 \mathrm{~nm}$ of Oil Red O stain extracted from stained leaf samples. 


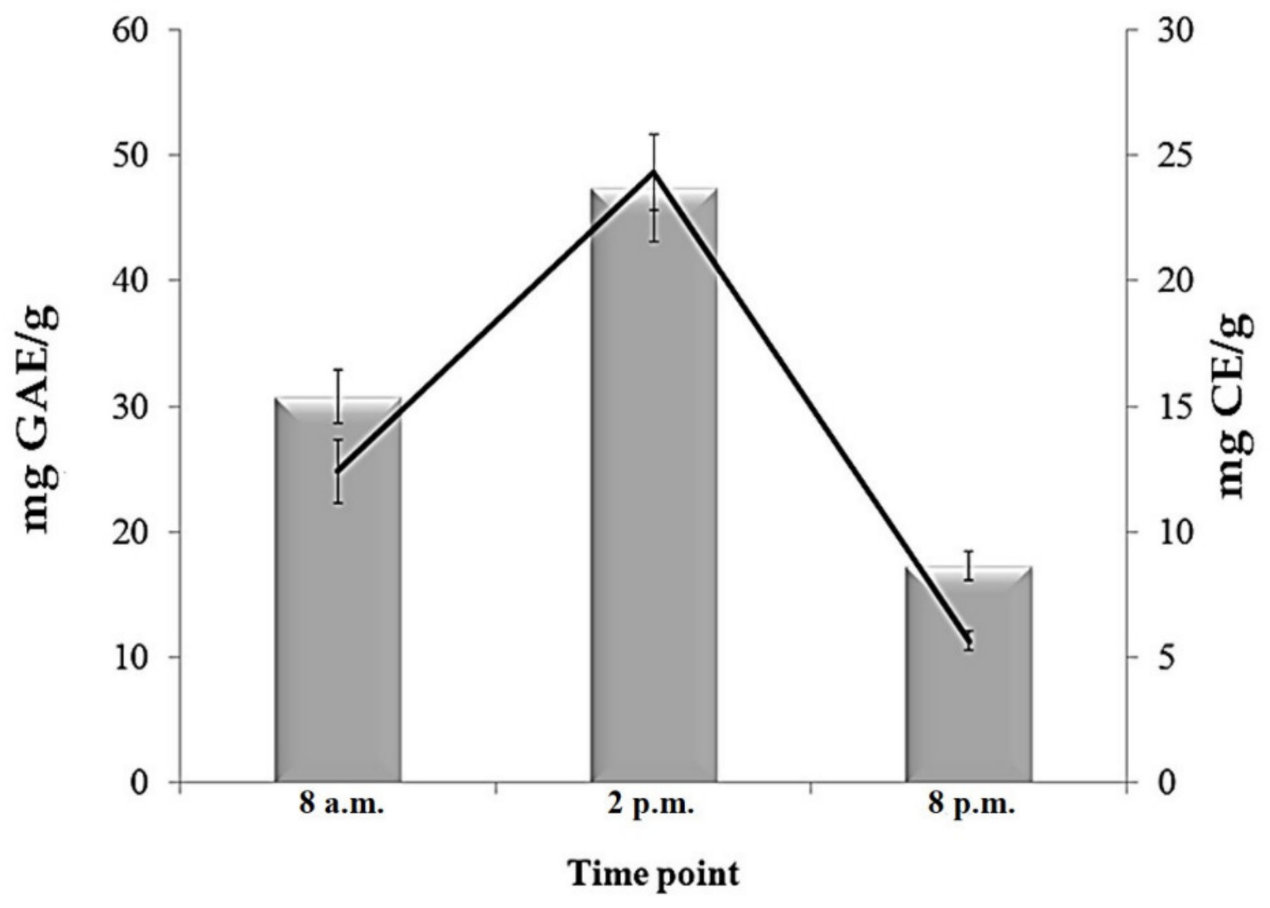

Figure 5. Total phenolics and total flavonoids contents in Plectranthus amboinicus leaf essential oil extracts (expressed as gallic acid equivalent (GAE) and catechin (CE) equivalent).

\subsection{GC-MS Analysis of Plectranthus amboinicus Essential Oil Extract}

GC-MS analysis of P. amboinicus essential oil extracted from leaves harvested at different time points was conducted to evaluate the influence of harvesting time on the chemical constituents present in the extracts. Twenty-five compounds were identified and categorized according to their phytochemical classes (Table 1 and Figure 6). Compositions of the essential oil constituents were found to be consistent at all time points and were dominated by carvacrol $(47.00-60.00 \%), \gamma$-terpinene $(8.00-10.00 \%)$, caryophyllene $(\sim 6.00 \%)$, p-cymene (4.90-6.50\%), trans- $\alpha$-bergamotene (4.70-5.00\%), and thymoquinone $(3.30-5.65 \%)$. From the GC-MS data, it can be seen that the percentages of carvacrol and thymoquinone, the monoterpene compounds, were higher in the leaves extracted at 2 p.m. than at the other time points. Carvacrol and thymoquinone have been studied for many years for their functional properties and bioactivities, including antioxidant and oxidative stress effects [21-23]. 
Table 1. Compounds identified from Plectranthus amboinicus leaf essential oil extract.

\begin{tabular}{|c|c|c|c|c|c|c|}
\hline \multirow{2}{*}{ Peak } & \multirow{2}{*}{ Compounds } & \multirow{2}{*}{$\mathrm{RT}^{\mathrm{a}}$ (min) } & \multirow{2}{*}{$\mathbf{R I}^{\mathbf{b}}$} & \multicolumn{3}{|c|}{ Harvesting Time/Relative Content ${ }^{\mathrm{c}}(\%)$} \\
\hline & & & & 8 a.m. & 2 p.m. & 8 p.m. \\
\hline & Monoterpene hydrocarbons & & & & & \\
\hline 1 & $\beta$-Thujene & 8.21 & 926 & 0.25 & 0.21 & 0.39 \\
\hline 2 & $\alpha$-pinene & 8.39 & 932 & 0.10 & 0.10 & 0.12 \\
\hline 3 & $\beta$-Myrcene & 10.17 & 991 & 0.47 & 0.41 & 0.63 \\
\hline 4 & $\alpha$-Phellandrene & 10.55 & 1004 & 0.17 & 0.14 & 0.17 \\
\hline 5 & $\alpha$-Terpinene & 10.93 & 1016 & 1.25 & 1.02 & 1.40 \\
\hline 6 & p-Cymene & 11.19 & 1025 & 5.42 & 5.03 & 6.44 \\
\hline 7 & Limonene & 11.30 & 1028 & 0.26 & 0.23 & 0.38 \\
\hline \multirow[t]{2}{*}{8} & $\gamma$-Terpinene & 12.26 & 1060 & 10.11 & 8.89 & 10.33 \\
\hline & Oxygenated monoterpenes & & & & & \\
\hline 9 & $\beta$-Terpineol & 12.50 & 1067 & 0.69 & 0.77 & 1.03 \\
\hline 10 & Thymoquinone & 17.90 & 1252 & 3.92 & 5.65 & 3.31 \\
\hline 11 & Thymol & 19.10 & 1296 & 0.51 & 0.49 & 0.27 \\
\hline \multirow[t]{2}{*}{12} & Carvacrol & 19.45 & 1309 & 59.25 & 59.79 & 48.13 \\
\hline & Sesquiterpene hydrocarbons & & & & & \\
\hline 13 & Caryophyllene & 22.43 & 1424 & 6.66 & 6.29 & 6.17 \\
\hline 14 & Trans- $\alpha$-Bergamotene & 22.80 & 1439 & 4.94 & 4.79 & 4.84 \\
\hline 15 & Humulene & 23.28 & 1458 & 1.86 & 1.80 & 1.75 \\
\hline 16 & (E)- $\beta$-Farnesene & 24.01 & 1487 & 0.12 & 0.11 & 0.14 \\
\hline \multirow[t]{2}{*}{17} & $\beta$-Bisabolene & 24.58 & 1511 & 0.26 & 0.26 & 0.26 \\
\hline & Oxygenated sesquiterpenes & & & & & \\
\hline 18 & $\begin{array}{l}\text { Caryophyllene oxide } \\
\text { Alkane and alcohol }\end{array}$ & 26.41 & 1590 & 0.96 & 1.08 & 1.11 \\
\hline 19 & 3-Methylcyclopentanol & 5.86 & 841 & 0.26 & 0.29 & 0.17 \\
\hline 20 & 4-Ethyl-octane & 9.07 & 954 & - & - & 0.37 \\
\hline 21 & 3-Ethyl-octane & 9.44 & 967 & - & - & 0.29 \\
\hline 22 & 3-methyl-nonane & 9.54 & 970 & - & - & 0.89 \\
\hline 23 & 1-Octen-3-ol & 9.86 & 980 & 0.54 & 0.63 & 0.51 \\
\hline 24 & 3,8-Dimethy decane & 15.56 & 1171 & - & - & 0.55 \\
\hline \multirow[t]{10}{*}{25} & 3-Methylpentadecane & 25.98 & 1571 & - & - & 0.35 \\
\hline & Chemical class & & & & & \\
\hline & Monoterpene hydrocarbons & & & 18.03 & 16.03 & 19.86 \\
\hline & Sesquiterpene hydrocarbons & & & 64.37 & 66.70 & 52.74 \\
\hline & Total monoterpenes & & & 82.40 & 82.73 & 72.60 \\
\hline & Sesquiterpene hydrocarbons & & & 13.84 & 13.25 & 13.16 \\
\hline & Oxygenated sesquiterpenes & & & 0.96 & 1.08 & 1.11 \\
\hline & Total sesquiterpenes & & & 14.80 & 14.33 & 14.27 \\
\hline & Others & & & 0.80 & 0.92 & 3.13 \\
\hline & Total & & & 98.00 & 97.98 & 90.00 \\
\hline
\end{tabular}

${ }^{a}$ Retention time (RT) in min; ${ }^{b}$ van Den Dool and Kratz retention index calculated for HP-5MS column; ${ }^{\mathrm{c}}$ Relative content expressed as a percentage of the peak area of the corresponding compound over the total peak areas of all identified volatiles. Only peaks with more than $0.1 \%$ of relative content are presented here. 

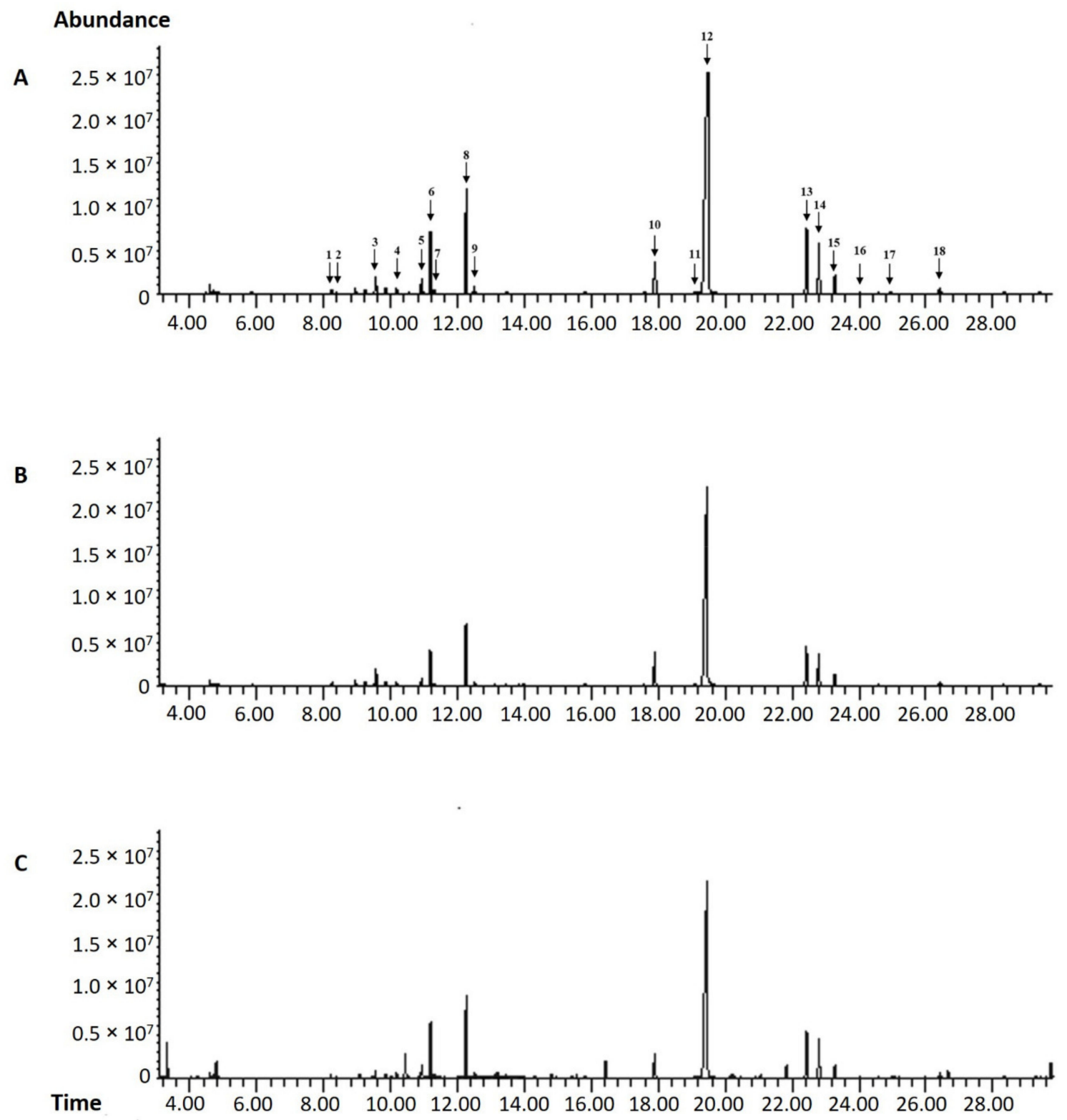

Figure 6. Chromatographic profiles of Plectranthus amboinicus essential oil extracted from leaves harvested at different time points. (A) 8 a.m.; (B) 2 p.m., and (C) 8 p.m. The numbers (as indicated by the black arrow) correspond to the terpenoids detected as described in Table 1.

The major constituents were constitutively present at relatively high percentages throughout the day, and they contributed to the unique, strongly aromatic oregano-like odor of the P. amboinicus leaves. Overall, there was no major qualitative variation in the chemical components related to the collection time except for the additional aliphatic alkane hydrocarbons present in the extract harvested at 8 p.m. (Table 1). Two isomeric phenols (carvacrol and thymol) are chemotypes that are frequently found in P. amboinicus [24,25]. Thus, based on these chemical constituents, the P. amboinicus in this study was classified as a carvacrol chemotype. Carvacrol is the signature chemical largely responsible for the sharp, pungent oregano-flavor of oregano, marjoram, and plants from other genera that are also considered as oreganos, such as Lippia graveolens (Mexican oregano) and P. amboinicus (Cuban oregano) [26]. This result was in accordance with the known volatile constituents of most P. amboinicus, as previously reviewed by Arumugam et al. [1]. The variations observed among various reports could be attributed to the different geographical features, climate, seasonal variations, genetic aspects, and extraction methods [1,27]. 
This result was consistent with our previous $P$. amboinicus leaf volatile profiles determined using HS-SPME, although the relative amounts of the individual components varied with $\alpha$-bergamotene, carvacrol, caryophyllene, $\mathrm{p}$-cymene, and $\gamma$-terpinene as major constituents [12]. Asiimwe et al. [28] revealed that the aqueous fraction of $P$. amboinicus leaves from Uganda extracted using SPME showed linalool (50.30\%) as the main compound in this plant. It was also evident that the P. amboinicus growing in the same locality could also exhibit chemical variations. Essential oil of P. amboinicus leaves from UPM Serdang analyzed by Erny Sabrina et al. [29] showed 3-carene (20.78\%), carvacrol (19.29\%), camphor $(17.96 \%), \gamma$-terpinene, $(8.94 \%), \alpha$-terpinene $(6.04 \%)$, and o-cymene $(5.06 \%)$ as the main components. In comparison, the wild P. amboinicus collected near the UPM Serdang forest area contained carvacrol $(37.73 \%)$, tetracontane $(16.67 \%)$, squalene $(15.64 \%)$, tetrapentacontane $(13.77 \%)$, and phytol (12.95\%) [30].

It is noteworthy that, in this study, we were able to detect thymoquinone (TQ) among other terpenoids from P. amboinicus. TQ was first identified from Nigella sativa black seed essential oil, and later was isolated from other plants such as O. vulgarae L. [31], O. syriacum [32-34], Satureja montana essential oil [35], aerial flowering parts of Thymus vulgaris [36], and Phytophthora ramorum [37]. TQ is known for its anticancer activity by deregulating both the mitogen-activated protein kinase (MAPK) and protein kinase B signaling pathways in squamous cell carcinoma [38] and human prostate cancer cell lines [39]. It also inhibits telomerase activity that causes unlimited replication of cancer cells by inducing telomere shortening and apoptosis in glioblastoma cell lines [40]. TQ has been identified as an adjuvant for combination anticancer therapy by enhancing the antitumor activity of chemotherapeutic drugs and/or decreasing their toxicity level similar to normal cells [41]. The presence of TQ in P. amboinicus was also documented by Chen et al. [42] in their water-hexane extract. This shows that TQ is a promising anticancer compound with significant potential for clinical translation. Thus, the presence of this compound in the local herb of $P$. amboinicus extract is a notable observation, revealing the nutritional value of this plant as a natural source of TQ and the plant's potential to be explored for anticancer drugs.

The TQ biosynthetic pathway in N. sativa was proposed by Botnick et al. [43] based on the better-studied pathway in the Lamiaceae [44]. It was suggested in this pathway that the GPP is probably cyclized to $\gamma$-terpinene, aromatized into p-cymene, followed by hydroxylation to carvacrol/thymol and thymohydroquinone, and oxidation to TQ [43]. The suggested model was supported by the succession in accumulation of the precursors, such as $\gamma$-terpinene, p-cymene, and carvacrol in N. sativa seeds [43]. However, thymohydroquinone was not detected in the hexane-extracted samples in this study, but was noted in our previous work using SPME [12]. Based on the abovementioned pathway, it is hypothesized that $\gamma$-terpinene might serve as a precursor for $\mathrm{p}$-cymene, whereas $\mathrm{p}$-cymene is a precursor for carvacrol in N. sativa, thyme, and oregano $[43,44]$. We noticed the same trends in the accumulation of $\gamma$-terpinene, $\mathrm{p}$-cymene, carvacrol, and TQ in P. amboinicus. This hypothesis was supported by a decrease in $\gamma$-terpinene and p-cymene levels in parallel to an increase in carvacrol and TQ (Table 1). Maximum TQ was detected at 2 p.m., and it was observed that a decrease in $\gamma$-terpinene and $\mathrm{p}$-cymene was accompanied by an increase in carvacrol and TQ. The minimum amount of TQ (3.31\%) was observed at 8 p.m., which coincided with a decrease in carvacrol and increased relative concentrations of $\gamma$-terpinene and p-cymene compared to the earlier time points. This trend was in agreement with Zein et al. [45], in which poor content of carvacrol in O. syriacum was accompanied by an increased rate of $\gamma$-terpinene and $\mathrm{p}$-cymene. Our finding was also consistent with $O$. vulgare $\mathrm{x}$ O. majorana, where $\gamma$-terpinene content followed the trend of p-cymene accumulation [46].

Light intensity and temperature are among the factors that could influence the quality and compositions of essential oil in Lamiaceae. Higher light intensity was reported to enhance the relative content of p-cymene in O. syriacum, whereas the content of thymol and $\gamma$-terpinene generally decreased [47]. Our findings showed an opposite trend, whereby p-cymene and $\gamma$-terpinene contents decreased under high light intensity (2 p.m.) and in- 
creased at night (8 p.m.). The same observation was reported by Shafiee-Hajiabad et al. [31] and Tibaldi et al. [48], in which the content of p-cymene increased in O. vulgarae L ssp. hirtum (Link) Ietswaart under reduced light conditions.

On the contrary, carvacrol and TQ accumulations were higher during midday and decreased at night, which could be related to the reduced temperature and light conditions. The higher level of carvacrol and thymoquinone in extract harvested at 2 p.m. may explain the increase in TFC and TPC in the sample (Figure 5). It was previously reported that the sudden temperature change in summer and winter seasons caused changes in the biosynthetic pathway, favoring the production of different metabolites such as phenolic compounds rather than essential oil production [49]. However, we were unable to establish a clear trend for this occurrence because the essential oil contents for samples harvested at 8 a.m. and 2 p.m. (Table 1) were comparable, with the highest TPC exhibited in the 2 p.m. extract. Therefore, more studies are necessary to establish a clear correlation between the essential oil content with TPC and TFC in P. amboinicus. In the carvacrol chemotype of Origanum, higher temperature favors the carvacrol hydroxylase, an enzyme that mediates carvacrol synthesis, leading to the increase in carvacrol and a decrease in p-cymene [50]. According to Shafiee-Hajiabad et al. [31], when the light intensity is reduced, the activity of carvacrol hydroxylase is diminished, resulting in a lower amount of carvacrol being synthesized. It was also reported that the lower activity of carvacrol hydroxylase at cooler temperature resulted in the accumulation of $\mathrm{p}$-cymene due to a bottleneck situation for the subsequent biosynthesis step [50].

However, it remains to be clarified whether the differential biosynthesis of carvacrol is regulated at the level of gene expression or rather simply due to plant response to environmental factors such as temperature and light intensity. Further studies on the expression of genes related to carvacrol biosynthesis in different tissues, and in response to biotic and abiotic elicitors, might provide additional insights and improve understanding of the regulation of carvacrol and monoterpene biosynthesis in P. amboinicus.

\section{Conclusions}

Plectranthus amboinicus is known to produce numerous volatile monoterpenes, such as $\gamma$-terpinene, $\alpha$-terpineol, carvacrol, and p-cymene, that are valuable for the pharmaceutical industry. Results in this study revealed that P. amboinicus chemical composition is considerably affected by the harvesting time. The chemical polymorphism in the oil indicates that environmental factors such as light exposure and temperature should be considered to ensure a consistent chemical quality of P. amboinicus extract. It is recommended to harvest this plant at midday, when the highest TPC and TFC levels are exhibited, in addition to the highest levels of thymoquinone and carvacrol. This study provides preliminary findings that can assist producers in determining a suitable harvesting time to ensure the plant is rich in the desired compounds for pharmaceutical and food industry applications.

Author Contributions: Conceptualization, J.O.A., M.-H.A.R. and K.S.L.; methodology, N.S.A., N.E.M., J.O.A., M.-H.A.R. and K.S.L.; validation, J.O.A. and K.S.L.; investigation, N.S.A., N.E.M. and A.H.A.; resources, J.O.A. and K.S.L.; writing-original draft preparation, N.S.A., A.H.A. and N.E.M.; writing—review and editing, N.S.A., N.E.M., J.O.A., M.-H.A.R. and K.S.L.; supervision, J.O.A. and K.S.L.; project administration, N.S.A., N.E.M. and J.O.A.; funding acquisition, N.S.A., J.O.A., M.-H.A.R. and K.S.L. All authors have read and agreed to the published version of the manuscript.

Funding: This research was funded by Ministry of Higher Education, Malaysia, Fundamental Research Grant Scheme, grant number FRGS/2/2014/STWN10/UPM/02/1 and UPM Putra Grant, grant number GP-IPS/2015/9463800.

Institutional Review Board Statement: Not applicable.

Informed Consent Statement: Not applicable.

Data Availability Statement: The data used to support the findings of this study are included within the article. 
Conflicts of Interest: The authors declare no conflict of interest. The funders have no role in the design of the study; in the collection, analyses, or interpretation of data; in the writing of the manuscript, or in the decision to publish the results.

\section{References}

1. Arumugam, G.; Swamy, M.K.; Sinniah, U.R. Plectranthus amboinicus (Lour.) Spreng: Botanical, Phytochemical, Pharmacological and Nutritional Significance. Molecules 2016, 21, 369. [CrossRef] [PubMed]

2. El Sohafy, S.M.; Metwally, A.M.; Omar, A.A.; Harraz, F.M. Phytochemical investigation and antimicrobial activity of Psidium guajava L. leaves. Pharmacogn. Mag. 2010, 6, 212-218. [CrossRef] [PubMed]

3. Khare, R.S.; Banerjee, S.; Kundu, K. Coleus aromaticus benth-A nutritive medicinal plant of potential therapeutic value. Int. J. Pharma. Bio Sci. 2011, 2, 488-500.

4. Damanik, R.; Wahlqvist, M.L.; Wattanapenpaiboon, N. Lactagogue effects of Torbangun, a Bataknese traditional cuisine. Asia Pac. J. Clin. Nutr. 2006, 15, 267-274. [PubMed]

5. De Oliveira, F.F.M.; Torres, A.F.; Gonçalves, T.B.; Santiago, G.M.P.; De Carvalho, C.B.M.; Aguiar, M.B.; Camara, L.M.C.; Rabenhorst, S.H.B.; Martins, A.M.C.; Junior, J.T.V.; et al. Efficacy of Plectranthus amboinicus (Lour.) Spreng in a Murine Model of MethicillinResistant Staphylococcus aureus Skin Abscesses. Evid. Based Complement. Altern. Med. 2013, 2013, 1-9. [CrossRef]

6. Hoehler, T.M. An Energy Balance Concept for Habitability. Astrobiology 2007, 7, 824-838. [CrossRef]

7. Gurgel, A.P.A.D.; da Silva, J.G.; Grangeiro, A.R.S.; Oliveira, D.C.; Lima, C.M.; da Silva, A.C.; Oliveira, R.A.; Souza, I.A. In vivo study of the anti-inflammatory and antitumor activities of leaves from Plectranthus amboinicus (Lour.) Spreng (Lamiaceae). J. Ethnopharmacol. 2009, 125, 361-363. [CrossRef]

8. Senthilkumar, A.; Venkatesalu, V. Chemical composition and larvicidal activity of the essential oil of Plectranthus amboinicus (Lour.) Spreng against Anopheles stephensi: A malarial vector mosquito. Parasitol. Res. 2010, 107, 1275-1278. [CrossRef]

9. Bhatt, P.; Joseph, G.S.; Negi, P.S.; Varadaraj, M.C. Chemical Composition and Nutraceutical Potential of Indian Borage (Plectranthus amboinicus) Stem Extract. J. Chem. 2013, 2013, 1-7. [CrossRef]

10. Oyedemi, S.O.; Okoh, A.I.; Mabinya, L.V.; Pirochenva, G.; Afolayan, A.J. The proposed mechanism of bactericidal action of eugenol, $\alpha$-terpineol and $\gamma$-terpinene against Listeria monocytogenes, Streptococcus pyogenes, Proteus vulgaris and Escherichia coli. Afr. J. Biotechnol. 2009, 8, 1280-1286. [CrossRef]

11. Dai, W.; Sun, C.; Huang, S.; Zhou, Q. Carvacrol suppresses proliferation and invasion in human oral squamous cell carcinoma. Onco Targets Ther. 2016, 9, 2297-2304. [CrossRef] [PubMed]

12. Ashaari, N.S.; Rahim, M.H.A.; Sabri, S.; Lai, K.S.; Song, A.A.-L.; Rahim, R.A.; Abdullah, W.M.A.N.W.; Abdullah, J.O. Functional characterization of a new terpene synthase from Plectranthus amboinicus. PLoS ONE 2020, 15, e0235416. [CrossRef] [PubMed]

13. Mohd-Hairul, A.R. Chemical Composition of Floral Volatiles and Expression of Scent-Related Genes in Vanda Mimi Palmer. Ph.D. Thesis, Universiti Putra Malaysia, Seri Kembangan, Malaysia, 2010.

14. Mohamad, N.E.; Yeap, S.K.; Lim, K.L.; Yusof, H.M.; Beh, B.K.; Tan, S.W.; Ho, W.Y.; Sharifuddin, S.A.; Jamaluddin, A.; Long, K.; et al. Antioxidant effects of pineapple vinegar in reversing of paracetamol-induced liver damage in mice. Chin. Med. 2015, 10, 1-10. [CrossRef] [PubMed]

15. Aguiar, J.; Gonçalves, J.L.; Alves, V.L.; Câmara, J.S. Chemical Fingerprint of Free Polyphenols and Antioxidant Activity in Dietary Fruits and Vegetables Using a Non-Targeted Approach Based on QuEChERS Ultrasound-Assisted Extraction Combined with UHPLC-PDA. Antioxidants 2020, 9, 305. [CrossRef]

16. Winter, K.; Holtum, J.A.M. Facultative crassulacean acid metabolism (CAM) plants: Powerful tools for unravelling the functional elements of CAM photosynthesis. J. Exp. Bot. 2014, 65, 3425-3441. [CrossRef]

17. Muthukumarana, R.; Dharmadasa, R. Pharmacognostical investigation of Plectranthus hadiensis (Forssk.) Schweinf. ex Sprenger. and Plectranthus amboinicus (Lour.) Spreng. World J. Agric. Res. 2014, 2, 240-246. [CrossRef]

18. Sharma, S.; Sangwan, N.S.; Sangwan, R.S. Developmental process of essential oil glandular trichome collapsing in menthol mint. Curr. Sci. 2003, 84, 544-550.

19. Lukhoba, C.W.; Simmonds, M.S.; Paton, A.J. Plectranthus: A review of ethnobotanical uses. J. Ethnopharmacol. 2006, 103, 1-24. [CrossRef]

20. Figueiredo, A.C.; Barroso, J.; Pedro, L.; Scheffer, J.J.C. Factors affecting secondary metabolite production in plants: Volatile components and essential oils. Flavour Fragr. J. 2008, 23, 213-226. [CrossRef]

21. Fanoudi, S.; Alavi, M.S.; Hosseini, M.; Sadeghnia, H.R. Nigella sativa and thymoquinone attenuate oxidative stress and cognitive impairment following cerebral hypoperfusion in rats. Metab. Brain Dis. 2019, 34, 1001-1010. [CrossRef]

22. Ashraf, S.S.; Rao, M.V.; Kaneez, F.S.; Qadri, S.; Al-Marzouqi, A.H.; Chandranath, I.S.; Adem, A. Nigella sativa Extract as a Potent Antioxidant for Petrochemical-Induced Oxidative Stress. J. Chromatogr. Sci. 2011, 49, 321-326. [CrossRef]

23. Yildiz, S.; Turan, S.; Kiralan, M.; Ramadan, M.F. Antioxidant properties of thymol, carvacrol, and thymoquinone and its efficiencies on the stabilization of refined and stripped corn oils. J. Food Meas. Charact. 2021, 15, 621-632. [CrossRef]

24. Khan, M.; Khan, S.T.; Khan, M.; Mousa, A.A.; Mahmood, A.; Alkhathlan, H.Z. Chemical diversity in leaf and stem essential oils of Origanum vulgare L. and their effects on microbicidal activities. AMB Express 2019, 9, 1-15. [CrossRef] 
25. Pinheiro, P.F.; Costa, A.V.; Alves, T.D.A.; Galter, I.N.; Pinheiro, C.A.; Pereira, A.F.; Oliveira, C.M.R.; Fontes, M.M.P. Phytotoxicity and Cytotoxicity of Essential Oil from Leaves of Plectranthus amboinicus, Carvacrol, and Thymol in Plant Bioassays. J. Agric. Food Chem. 2015, 63, 8981-8990. [CrossRef]

26. Meyers, M. Oregano and Marjoram: An Herb Society of America Guide to the Genus Origanum. Herb Soc. Am. 2005, 1-66. Available online: https: / / www.herbsociety.org (accessed on 25 May 2021).

27. Lopes, P.Q.; Carneiro, F.B.; De Sousa, A.L.B.; Santos, S.G.; Oliveira, E.E.; Soares, L.A.L. Technological Evaluation of Emulsions Containing The Volatile Oil from Leaves of Plectranthus Amboinicus Lour. Pharmacogn. Mag. 2017, 13, $159-167$.

28. Asiimwe, S.; Karlsson, A.B.; Azeem, M.; Mugisha, K.M.; Namutebi, A.; Gakunga, N.J. Chemical composition and toxicological evaluation of the aqueous leaf extracts of Plectranthus amboinicus Lour. Spreng. Int. J. Pharm. Sci. Invent. 2014, 3, 19-27.

29. Erny Sabrina, M.N.; Razali, M.; Mirfat, A.H.S.; Mohd Shukri, M.A. Antimicrobial activity and bioactive evaluation of Plectranthus amboinicus essential oil. Am. J. Res. Commun. 2014, 2, 121-127.

30. Swamy, M.K.; Arumugam, G.; Kaur, R.; Ghasemzadeh, A.; Yusoff, M.M.; Sinniah, U.R. GC-MS Based Metabolite Profiling, Antioxidant and Antimicrobial Properties of Different Solvent Extracts of Malaysian Plectranthus amboinicus Leaves. Evid. Based Complement. Altern. Med. 2017, 2017, 1-10. [CrossRef] [PubMed]

31. Shafiee-Hajiabad, M.; Novak, J.; Honermeier, B. Content and composition of essential oil of four Origanum vulgare L. accessions under reduced and normal light intensity conditions. J. Appl. Bot. Food Qual. 2016, 89, 126-134. [CrossRef]

32. Ibrahim, L.; Karaky, M.; Ayoub, P.; El Ajouz, N.; Ibrahim, S. Chemical composition and antimicrobial activities of essential oil and its components from Lebanese Origanum syriacum L. J. Essent. Oil Res. 2012, 24, 339-345. [CrossRef]

33. Zein, S. Variation of thymol, carvacrol and thymoquinone production from wild and cultivated Origanum syriacum of South Lebanon. J. Med. Plants Res. 2012, 6, 1692-1696. [CrossRef]

34. Lukas, B.; Schmiderer, C.; Franz, C.; Novak, J. Composition of Essential Oil Compounds from Different Syrian Populations of Origanum syriacum L. (Lamiaceae). J. Agric. Food Chem. 2009, 57, 1362-1365. [CrossRef]

35. Grosso, C.; Figueiredo, A.C.; Burillo, J.; Mainar, A.M.; Urieta, J.S.; Barroso, J.G.; Coelho, J.A.; Palavra, A.M.F.; Grosso, A.C.; Fernández, A.M.M. Enrichment of the thymoquinone content in volatile oil from Satureja montana using supercritical fluid extraction. J. Sep. Sci. 2009, 32, 328-334. [CrossRef] [PubMed]

36. Grosso, C.; Figueiredo, A.C.; Burillo, J.; Mainar, A.M.; Urieta, J.S.; Barroso, J.; Coelho, J.A.; Palavra, A.M.F. Composition and antioxidant activity of Thymus vulgaris volatiles: Comparison between supercritical fluid extraction and hydrodistillation. J. Sep. Sci. 2010, 33, 2211-2218. [CrossRef]

37. Manter, D.K.; Kelsey, R.G.; Karchesy, J.J. Antimicrobial Activity of Extractable Conifer Heartwood Compounds Toward Phytophthora ramorum. J. Chem. Ecol. 2007, 33, 2133-2147. [CrossRef]

38. Das, S.; Dey, K.K.; Dey, G.; Pal, I.; Majumder, A.; MaitiChoudhury, S.; Kundu, S.C.; Mandal, M. Antineoplastic and Apoptotic Potential of Traditional Medicines Thymoquinone and Diosgenin in Squamous Cell Carcinoma. PLoS ONE 2012, 7, e46641. [CrossRef]

39. Yi, T.; Cho, S.-G.; Yi, Z.; Pang, X.; Rodriguez, M.; Wang, Y.; Sethi, G.; Aggarwal, B.B.; Liu, M. Thymoquinone inhibits tumor angiogenesis and tumor growth through suppressing AKT and extracellular signal-regulated kinase signaling pathways. Mol. Cancer Ther. 2008, 7, 1789-1796. [CrossRef]

40. Gurung, R.L.; Ni Lim, S.; Khaw, A.K.; Soon, J.F.F.; Shenoy, K.; Ali, S.M.; Jayapal, M.; Sethu, S.; Baskar, R.; Hande, M.P. Thymoquinone Induces Telomere Shortening, DNA Damage and Apoptosis in Human Glioblastoma Cells. PLoS ONE 2010, 5 , e12124. [CrossRef]

41. Schneider-Stock, R.; Fakhoury, I.H.; Zaki, A.M.; El-Baba, C.; Gali-Muhtasib, H.U. Thymoquinone: Fifty years of success in the battle against cancer models. Drug Discov. Today 2014, 19, 18-30. [CrossRef] [PubMed]

42. Chen, Y.-S.; Yu, H.-M.; Shie, J.-J.; Cheng, T.-J.R.; Wu, C.-Y.; Fang, J.-M.; Wong, C.-H. Chemical constituents of Plectranthus amboinicus and the synthetic analogs possessing anti-inflammatory activity. Bioorg. Med. Chem. 2014, 22, 1766-1772. [CrossRef] [PubMed]

43. Botnick, I.; Xue, W.; Bar, E.; Ibdah, M.; Schwartz, A.; Joel, D.M.; Lev, E.; Fait, A.; Lewinsohn, E. Distribution of Primary and Specialized Metabolites in Nigella sativa Seeds, a Spice with Vast Traditional and Historical Uses. Molecules 2012, 17, 10159-10177. [CrossRef] [PubMed]

44. Crocoll, C.; Asbach, J.; Novak, J.; Gershenzon, J.; Degenhardt, J. Terpene synthases of oregano (Origanum vulgare L.) and their roles in the pathway and regulation of terpene biosynthesis. Plant Mol. Biol. 2010, 73, 587-603. [CrossRef]

45. Zein, S.; Awada, S.; Rachidi, S.; Hajj, A.; Krivoruschko, E.; Kanaan, H. Chemical analysis of essential oil from Lebanese wild and cultivated Origanum syriacum L. (Lamiaceae) before and after flowering. J. Med. Plants Res. 2011, 5, 379-387.

46. Novák, J.; Lukas, B.; Franz, C. Temperature Influences Thymol and Carvacrol Differentially in Origanum spp. (Lamiaceae). J. Essent. Oil Res. 2010, 22, 412-415. [CrossRef]

47. Dudai, N.; Putievsky, E.; Ravid, U.; Palevitch, D.; Halevy, A.H. Monoterpene content in Origanum syriacum as affected by environmental conditions and flowering. Physiol. Plant. 1992, 84, 453-459. [CrossRef]

48. Tibaldi, G.; Fontana, E.; Nicola, S. Growing conditions and postharvest management can affect the essential oil of Origanum vulgare L. ssp. hirtum (Link) Ietswaart. Ind. Crop. Prod. 2011, 34, 1516-1522. [CrossRef] 
49. Dehsheikh, A.B.; Sourestani, M.M.; Dehsheikh, P.B.; Vitalini, S.; Iriti, M.; Mottaghipisheh, J. A Comparative Study of Essential Oil Constituents and Phenolic Compounds of Arabian Lilac (Vitex Trifolia var. Purpurea): An Evidence of Season Effects. Foods 2019, 8, 52. [CrossRef] [PubMed]

50. Kokkini, S.; Karousou, R.; Dardioti, A.; Krigas, N.; Lanaras, T. Autumn essential oils of Greek oregano. Phytochemistry 1997, 44, 883-886. [CrossRef] 